\title{
APPLYING FORMATIVE ASSESSMENT STRATEGIES IN THE TEACHING OF POETRY: AN EXPERIMENT WITH THIRD-YEAR ENGLISH STUDIES STUDENTS AT THE UNIVERSITY OF LIMPOPO
}

\author{
N. E. Nkealah \\ Division of Research Development and Administration \\ University of Limpopo \\ Sovenga, South Africa \\ e-mail: naomi.nkealah@gmail.com
}

\section{ABSTRACT}

One of the most fundamental aspects to effective teaching and learning is formative assessment. Theorists in the field of assessment have recognised the value of formative assessment in higher education. This article reports on an experiment conducted with third-year English Studies students at the University of Limpopo which involved the designing and implementation of a formative task in a poetry class. Detailed feedback on the formative task was provided to students to help them improve their poetry essays. Students' final essays were then graded following an assessment rubric designed and disseminated to students. The results indicate that the practical implementation of formative assessment strategies led to students achieving high academic performance and acquiring lifelong skills. The study concludes that the innovative application of formative assessment in teaching has the potential to boost transformation in Higher Education Institutions.

Keywords: feedback, formative assessment, summative assessment, teaching and learning, University of Limpopo

\section{INTRODUCTION}

Implementing innovative teaching strategies are critical to enhancing transformation in Higher Education Institutions (HEIs). According to the Higher Education Quality Committee (HEQC), transformation in the South African higher education context refers to "quality higher education that develops the capabilities of individual learners for personal enrichment" (Symes 2006, 763). This means that the benefits of a transformational education should be evident in the world outside the university. It also implies that when students exit the university they should be empowered with both knowledge and skills to function effectively in the work environment - whether in the public or private sector. Therefore, in a case where students at third year level cannot demonstrate competence in basic life skills such as interpreting instructions and writing comprehensibly, then there is clearly a need for some form of intervention geared at skills development. This was the case with third year English Studies (ES) students at the University 
of Limpopo at the time this study was conducted.

Observations of the written work of third-year ES students in 2012 and 2013 revealed that these students had difficulties writing comprehensible essays in English, referencing their sources, understanding and interpreting essay topics, using textual evidence to formulate arguments, structuring their essays to exhibit coherence, weaving secondary material seamlessly into their essays, and interpreting texts in relation to specific literary theories. Problems with their English language expression included not only spelling and grammatical inaccuracies but also technical matters such as punctuation, paragraphing, pagination, and presentation of material in a logical format. The most distressing problem observed in students' writing, however, was plagiarism. This practice was prevalent across all levels, from first year to masters. For example, in a third-year poetry class of 24 students in 2012, almost every student's assignment script had evidence of plagiarised material. Notes from Sparknotes, Wiki.how and several other internet sites were simply downloaded and printed, in most cases without any attempt to reformulate the arguments to meet the requirements of the given essay topic. The result usually was the submission of essays that were irrelevant to the essay topic, extraneous to lifelong learning, and uncritical in their conceptualisation of arguments.

These were students on the verge of exiting the university as graduates, without having acquired learning beyond the traditional understanding of passing a module. It is disturbing to note that young people come to the university lacking the skills needed to cope with the demands of tertiary education (Akoojee and Nkomo 2007; Ribbens 2008), but it is even more alarming to see them leave the university underprepared for the rigours of postgraduate studies or devoid of values such as honesty and hard work which are fundamental to success in the work environment. Considering all of this, it becomes necessary to reconceptualise the role that assessment plays in the higher education system (Pryor and Lubisi 2002).

Assessment plays a fundamental role in fostering effective learning. Ramsden $(1992,182)$ states that "assessment is a way of teaching more effectively through understanding exactly what students know and do not know". Assessment therefore serves not just to evaluate the extent to which students have understood course content and can reconstruct or apply it when required to, but also to assist lecturers to better meet the needs of students by directing teaching to target specific weaknesses that hamper students' learning (Ramsden 1992; Shepard 2000). In this case, assessment exists in two forms: assessment of learning which has a summative function and assessment for learning which is formative (Black and Wiliam 2009; Bennett 2011).

The problem with assessment at UL was that assessment practices were not promoting quality teaching and learning, because although formative assessment (FormA) existed in 
principle, in practice summative assessment (SummA) dominated. According to an audit report on UL (Council for Higher Education 2011), the tangible application of FormA was absent across the university and, in some cases, staff did not understand what FormA entailed. The report states: "All assessments appear to be summative. The misunderstanding of the nature and purpose of formative assessment was found to be widespread" (Council for Higher Education 2011, 27). There was clearly a need to rethink teaching to include the practical use of FormA to enhance learning for students. The need to enhance lifelong learning for students, while simultaneously improving pass rates and developing academic skills, necessitated the execution of an experiment in which FormA strategies were implemented in teaching students in a thirdyear poetry class in 2014. An essay topic was given for assignment, students' essays were read and formative feedback provided, and final essays were then submitted for grading. Three FormA strategies were applied in the course of the experiment: constructive alignment (Biggs 1999), transparency in assessment (Knight 2001), and effective feedback (Nicol and Macfarlane-Dick 2006). Applying these strategies was an attempt to both improve students' learning and teach students values such as academic honesty, independent thinking, hard work, and belief in the self. This article presents the results of the experiment and discusses the implications they have for FormA theory and practice in HEIs and UL in particular. Before presenting the results, it is important to review some pertinent literature on assessment, to locate the study within its specific conceptual framework, and to outline the methodology that guided the study.

\section{LITERATURE REVIEW}

Simply put, FormA is assessment aimed, not at separating the wheat from the weeds, as it were, by determining which students proceed to the next level, but at collectively assisting students to understand subject content and apply knowledge. Formative tasks assigned to students are intended to elicit responses through which lecturers are able to identify gaps in students' knowledge and consequently modify their teaching to address those gaps (Yorke 2003; Nicol and Macfarlane-Dick 2006). The heartbeat of FormA is the provision of meaningful, customised feedback to students. This feedback enables them to see their mistakes in the current task, correct them in the next task, and eventually perform better in a SummA. Several scholars agree that using FormA in combination with SummA is a more effective way of enhancing teaching and learning (T\&L) than relying on SummA only (e.g. Gibbs 1999; Abrams 2007; Black and Wiliam 2009). Cizek $(2010,4)$ notes several disadvantages of teaching that relies on SummA only, stating that SummA is neither intended nor well-suited "to provide individual diagnostic information about students, to yield effective remediation recommendations, [and] 
to identify specific areas for individualizing instruction". The reason for this is that SummA is high-stakes assessment by which marks are the sole indicators of high or low student performance, and the marks represent a finality that does not envisage the possibility of students making improvements within the same assessment task.

In contrast to SummA, FormA gives the instructor access into the difficulties students are facing, allowing the instructor to model teaching in ways that address these difficulties. This is because FormA is low-stakes assessment, meaning that it is not administered for grading purposes per se (Knight 2001). As existing literature shows, FormA is not to be seen as a single practice but rather as a series of practices integrated into an existing pedagogic practice to enhance learning. Contesting dominant definitions of FormA which construct it as a defined process, Bennett $(2011,7)$ states that FormA is "neither a test nor a process, but some thoughtful integration of process and purposefully designed methodology or instrumentation". The suggestion emanating from this assertion is that FormA can be implemented as an intervention plan in cases where student learning is hampered by personal and institutional challenges as well as linguistic and psychosocial limitations, as in the case of third-year ES students at UL.

Many studies have been conducted across the world which demonstrate the rewards of FormA in teaching and learning in different contexts, including classroom and online teaching contexts. A study in China found that applying FormA in an English writing class helped students to improve their writing in terms of developing thesis statements, organising paragraphs, using appropriate vocabulary, and constructing complex sentences in their writing (Liu 2013). Similar results were registered in a conversation class in Japan where FormA tasks were also used in teaching English as a foreign language (Wilson 2014). In the online teaching context, FormA has been found to be effective in providing instructors with a medium for aligning assessment with teaching and learning, thereby engendering pedagogical changes in which learning and assessment complement each other (Gikandi, Morrow and Davis 2011). In a South African study in which weekly formative computer-based assessments were administered to students for eight weeks before the commencement of lectures, it was found that teaching and learning were optimised, since students' responses to the tasks enabled lecturers to determine students' knowledge and capacity and, in response, adjust their teaching in ways that minimised "rudimentary concepts" and instead included more "cognitively demanding tasks" as well as "critical questions" (Leach 2014, 1044). The examples from China, Japan and South Africa all point to the benefits of applying FormA in T\&L within HEIs.

\section{CONCEPTUAL FRAMEWORK}

In the context of this experiment, FormA is conceptualised as assessment that meets two criteria 
which have to do with the time of administration and the purpose for which the assessment is intended. So first, the assessment is administered at the beginning or middle of instruction and, second, it is intended to identify students' weaknesses so that subsequent instruction can be modified to assist students to revise their work, develop a sense of responsibility for their own learning, boost their self-perception, and gain self-evaluation skills (Shepard 2000; Cizek 2010). The conceptual framework within which this experiment is located combines three important strategies of assessment in higher education: constructive alignment, transparency in assessment, and effective feedback.

According to Biggs $(1999,69)$, "lack of alignment is a major reason why students adopt a surface approach to learning". From this, one infers that where there is no alignment between course objectives and outcomes on the one hand and assessment on the other hand, students miss out on effective learning. By contrast, where there is a direct correlation between the course objectives and the course outcomes, between the course outcomes and the learning activities and between the learning activities and the assessment tasks, then students are encouraged to maximize learning.

The importance of transparency in assessment is captured in the assessment model known as criterion-referenced assessment (CRA). According to Knight (2001, 18), the theory that informs CRA is simple: "identify what counts as successful performance or good attainment, specify it precisely and judge evidence of achievement accordingly". In this form of assessment, therefore, the lecturer sets a task and also designs the criteria by which the students' work will be judged. The criteria are made available to the students before they complete the assessment task. In this way, they become aware of the standards by which their work will be assessed. CRA is central to outcomes-based education which believes that "quality assessment should be transparent" (Meyer et al. 2010, 45). Transparency is, therefore, crucial for effective assessment practice within the South African higher education system.

Lastly, what lecturers provide to students as feedback must be useful to them, understandable by them and implementable with them. Nicol and Macfarlane-Dick (2006) list seven principles of good feedback practice: the feedback should clarify for students what good performance is (criteria), facilitate their development of self-assessment (reflection), deliver high quality information about their learning, encourage positive motivational beliefs and selfesteem, provide opportunities to bridge the gap between current and desired performance, and provide information to teachers to help them shape their teaching. 
Applying FormA in the ES poetry classroom at UL involved integrating these three strategies into a single framework that guided the design of appropriate tasks. Figure 1 captures the integration of the three strategies as they inform FormA practice in this experiment.

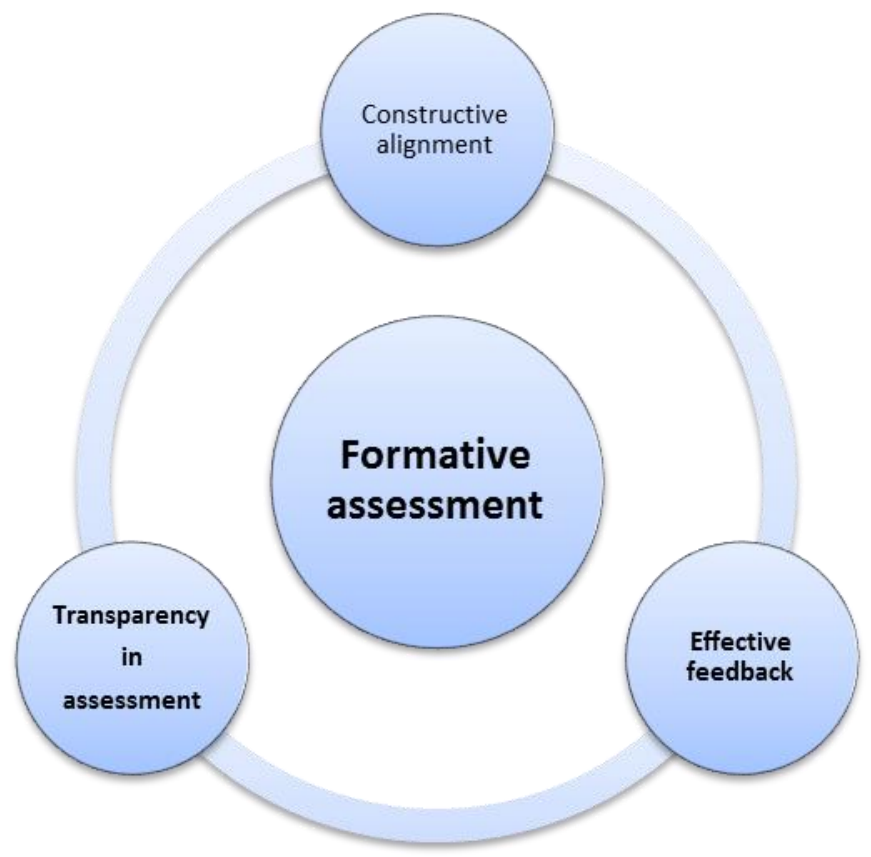

Figure 1: Formative assessment strategies applied in teaching poetry

\section{METHODOLOGY}

\section{The experimental design}

This experiment took the form of an intervention, with the purpose of addressing the prevalence of plagiarism and poor academic writing among the ES students, which often resulted in low pass rates. The intervention therefore had three major aims: first, to deepen students' understanding of content knowledge and thereby boost pass rates; secondly, to encourage independent critical thinking; and lastly to teach academic skills necessary for future independent learning as well as social values. These aims were in line with the recommendation by Black and Wiliam $(2009,18)$ that "the aims of any instruction are usually a combination of aims specific to the subject and aims directed to improving learning skills".

The ultimate objective of the intervention was to enforce reform or, to borrow the words of Wolcott $(1992,15)$, "to bring about change directed at improvement". Such a reformist approach to intervention ensures that students are empowered in the classroom, because they experience learning in a new way. In this new learning context, some decentralisation takes place because power shifts from the instructors to the students so that what emerges is "a system 
that actively encourages participation and ownership by all participants" (Brydon-Miller et al. 2013, 366). Thus, the conceptual framework necessitated that the experiment be designed as part of ongoing classroom teaching.

\section{The experimental process}

The experiment was limited to only the first lesson in the course outline since it was envisaged that the lessons learned from this lesson were to be applied in subsequent lessons. At the start of the course, students were given course outlines with clearly delineated assessments. The lecturer commenced lectures with the class of 30 students on 31 January 2014 and the first lesson, as indicated in the course outline, centred on politics and history in South African poetry in English. Lectures on the topic were presented in three weeks and the critical analysis explored two poems: Olive Schreiner's “The Cry of South Africa” and Sipho Sepamla's “The Loneliness Beyond". The choice of the poems was motivated by the need to help students understand that the devastating effects of colonialism on South Africa was a matter of concern to writers across different races, genders and social classes. The following was the topic for the students' essay assignment:

"South African poetry in English exposes the malaise of colonialism. Using the two poems, 'The Cry of South Africa' and 'The Loneliness Beyond', illustrate the validity of this assertion."

In terms of applying FormA strategies, the assignment topic was designed to prompt students to relate the poems to historical events in South Africa. It was therefore necessary for them to provide a historical background for each poem, showing how politically-charged historical events influenced poetic composition during South Africa's colonial days - from pre-apartheid to apartheid. The topic was aligned to the outcome of the teaching task which stated that students should be able to explicate the ways in which poetry produced in the colonial period was largely influenced by political and historical events. Students' analyses of the poems were to be underpinned by two major historical tragedies: the South African War (formerly the Anglo-Boer War) of 1899-1902 between the British and Dutch colonisers and the apartheid policy of racial segregation established by the National Party in 1948. Lecture notes explained clearly the difference between colonialism and apartheid as well as the interconnection between the two, and students were to apply this in their analyses of the two poems which had different and yet similar historical contexts. Students were informed that their initial essays would not be graded but would rather be reviewed as drafts. Final essays were to be submitted after feedback had been applied.

The course outline provided clear directives on how students should present their essays. 
There were specifications about font size, line spacing and length. For example, in terms of length, the essay had to be a maximum of five pages in order to limit possibilities of repetition of ideas and inclusion of irrelevant content (possibly sourced from the internet). Students had to submit their essays via the UL course management system known as Blackboard. Email submissions were accepted from students who encountered difficulties using the system. Electronic submission of essays allowed the lecturer to read the essays in their soft, rather than hard, copies and to type out comments at appropriate places.

The feedback comments on students' individual essays addressed the following five key areas:

1. Conceptualisation: it was clarified for students that the concept of colonialism as a malaise required explaining and historical contextualisation right at the beginning of the essays. A central argument had to be made upfront, depending on whether the stated assertion was deemed valid or not, and the poems analysed in ways that build up this argument. Specific textual evidence had to be referenced to substantiate claims made.

2. Language: the presentation of arguments had to be in coherent, comprehensible English, and errors - both grammatical and stylistic - had to be minimised.

3. Technicalities: quotations from the prescribed poems had to be indicated by the use of quotation marks, and the titles of poems also had to be in quotation marks. The term "the speaker" had to be used when referring to the voice in the poem, rather than "the writer". Quotations from the poems as well as from any scholarly source had to be explained and the link to the central argument established. The appropriate term to use when citing the poem's content was "lines" and not "sentences".

4. Presentation: essays had to respect the directives stipulated in the course outline with regard to length, font size and spacing.

5. Lifelong skills and values: ideas borrowed from other sources had to be acknowledged to avoid charges of plagiarism. Academic honesty was a key value to be upheld in writing the essays. Each essay had to follow the standard structure of having an introduction, a body and a conclusion, even though these did not have to be stated as subheadings. The revision guidelines were to be strictly followed, and students were not to engage in copy work and/or plagiarism.

Besides the personalised feedback on individual essay scripts, there was general feedback given to the class through a written document that clearly outlined the correct structure that the revised essays should have. This document was discussed in class and then uploaded onto Blackboard 
for students to be able to access it any time. The provision of a feedback document was in consonance with scholarly views that for feedback to be useful, there must be clear directives on how students can bridge the gap between current performance and desired performance (Nicol and Macfarlane-Dick 2006; Black and Wiliam 2009). Classroom discussions involved direct verbal feedback from the instructor and peer review in which students commented on potions of texts elicited from selected students' essays. In addition, practical work which focused on correct referencing enabled students to engage in self-assessment. According to Marshall (2007, 139), such classroom interactions enable the lecturer to provide scaffolding through which students develop their own capabilities and allows students "to gain insight into what is involved in ... a good essay". Figure 2 presents the design of the feedback system that was implemented.

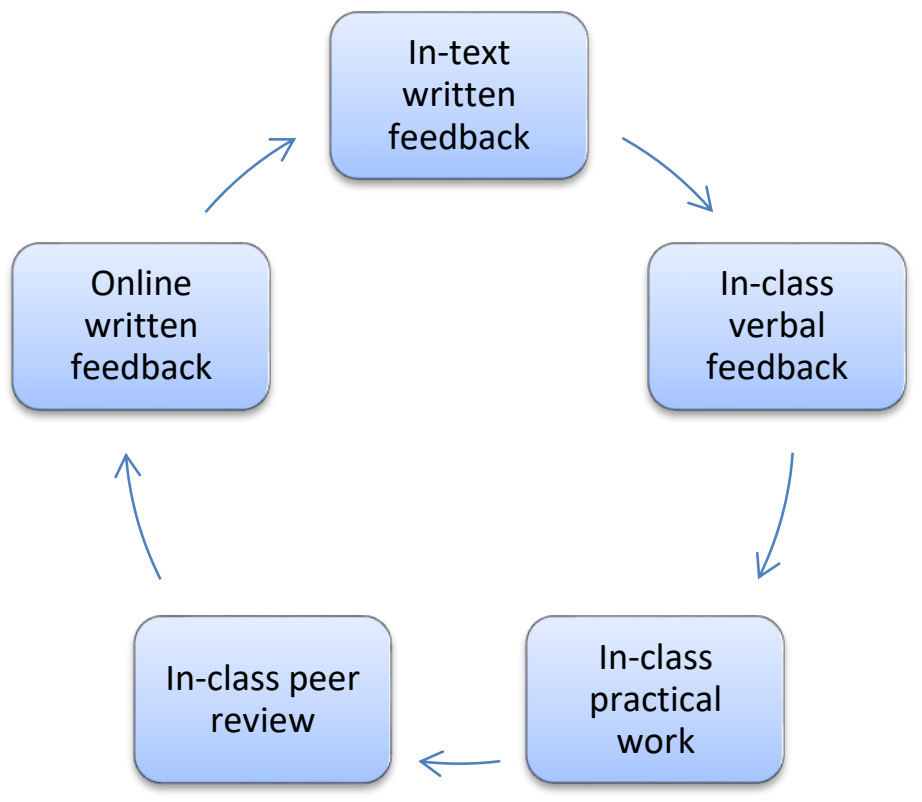

Figure 2: The feedback system

Students received their reviewed essays back electronically and were required to submit revised versions in hard copy for grading purposes. The criteria for assessing the revised essays were clearly outlined in a document which was then uploaded onto Blackboard. The criteria allocated 50 per cent for content, 20 per cent for language use, 20 per cent for presentation, and 10 per cent for values and attitudes. Content involved evidence of a critical assessment of the poems, highlighting how the poems conveyed the major theme of colonialism as a malaise and providing relevant textual evidence to substantiate arguments. Language use revolved on matters of syntax, grammar, spelling, punctuation, vocabulary, and appropriate academic register. Presentation referred to stylistic presentation of essay, with emphasis on cover page, 
pagination, layout of headings and subheadings, line spacing, margins, and paragraphing. Lastly, values and attitudes assessed matters of academic honesty and poetic ethics: no plagiarism; no use of offensive language; respect for authors and their works (e.g. by using authors' surnames rather than first names, spelling their names correctly, putting their poems in quotation marks, and capitalising initial and major words in poems); knowing the difference between "the speaker" and "the poet"; and quoting "lines" rather than "sentences". Following this criteria, the grading was divided into five levels of achievement:

$$
\begin{aligned}
& \text { Excellent }-75 \%-100 \% \\
& \text { Sound }-66 \%-74 \% \\
& \text { Adequate }-50 \%-65 \% \\
& \text { Borderline }-40 \%-49 \% \\
& \text { Clear fail }-0 \%-39 \%
\end{aligned}
$$

The final submitted essays were marked and scores recorded.

\section{Data collection}

The data collected during the experiment was both quantitative and qualitative, and the purpose of combining the two was to determine two things: (1) if the FormA task had assisted the students in achieving good academic performance in the subsequent SummA; and (2) if it hard helped them to learn lifelong skills. The quantitative data was elicited from the marks awarded for the essays in the SummA. It must be reiterated here that the same FormA task was subsequently administered as a SummA task in order to allow students to apply knowledge gained and skills learned in the FormA. Since FormA is low-stakes assessment for which the purpose is student development rather than grading, the one way to navigate the university system which required mainly SummA in order to determine who proceeds to the next level and who does not (in other words, to separate the wheat from weeds) was to re-issue the FormA task as a SummA task. As SummA, the essays were marked by two assessors and marks were recorded. The first set of marks is those by the first assessor - the lecturer - whose marks were those submitted to the department for the calculation of the final semester marks. However, for the purpose of ensuring the reliability of the scores, the final essays were also subjected to assessment by a second assessor who was neither involved in the teaching process nor was apprised of the purpose of the evaluation. The marks by this assessor and those by the first assessor were analysed comparatively to ascertain the consistency of passes and fails in their application of the marking criteria. 
Qualitative data was collected with the use of a questionnaire. The questionnaire was semi-structured, including both structured questions with possible answers from which students had to choose an appropriate answer and open-ended questions to which they had to provide personal responses. Again, to ensure the reliability of the data, the questionnaire was administered only after final essays had been graded and students notified of their marks. This was so that students' responses were not influenced by expectations of receiving higher marks as a reward for completing the questionnaire. Students were also told not to put their names on the questionnaire and were advised to complete it only if they so wished. The purpose of the questionnaire was to determine the extent to which the formative task had been beneficial to the students: the specific ways in which it helped them, the type of feedback they found most useful, and what new skills they had acquired in the course of the exercise. Students were informed that their responses to the questions were to be used solely for research purposes and the anonymity of their identities was guaranteed.

In addition to students' own responses, more qualitative data was collected through a document analysis process in which students' draft essays were compared against final essays to deduce the specific areas in which they had applied the given feedback. The findings from both the questionnaires and documents are presented below in a descriptive report.

\section{RESULTS}

\section{Essay scores}

Students' final essays were graded by two assessors: Assessor 1 (A1) and Assessor 2 (A2). As mentioned earlier, the aim was to determine if there was consistency in terms of passing or failing the students. Following the assessment criteria, the first assessor registered a pass rate of 63.33 per cent for content (19 passes and 11 fails), 100 per cent for language (30 passes and 0 fails), 96.67 per cent for presentation (29 passes and 1 fail), and 86.67 per cent for values and attitudes (26 passes and 4 fails). In terms of total scores, this assessor recorded a pass rate of 76.67 per cent ( 23 passes) and a fail rate of 23.33 per cent ( 7 fails). In comparison, the second assessor registered a 100 per cent for all the assessment rubrics, resulting in a 100 per cent pass rate. The overall marks of both assessors are consistent in showing a high academic performance of the ES students, both pitching at the Excellent scale (75\%-100\%) of the assessment criteria. The graph in Figure 3 summarises the assessors' pass rates for each marking rubric and overall. 


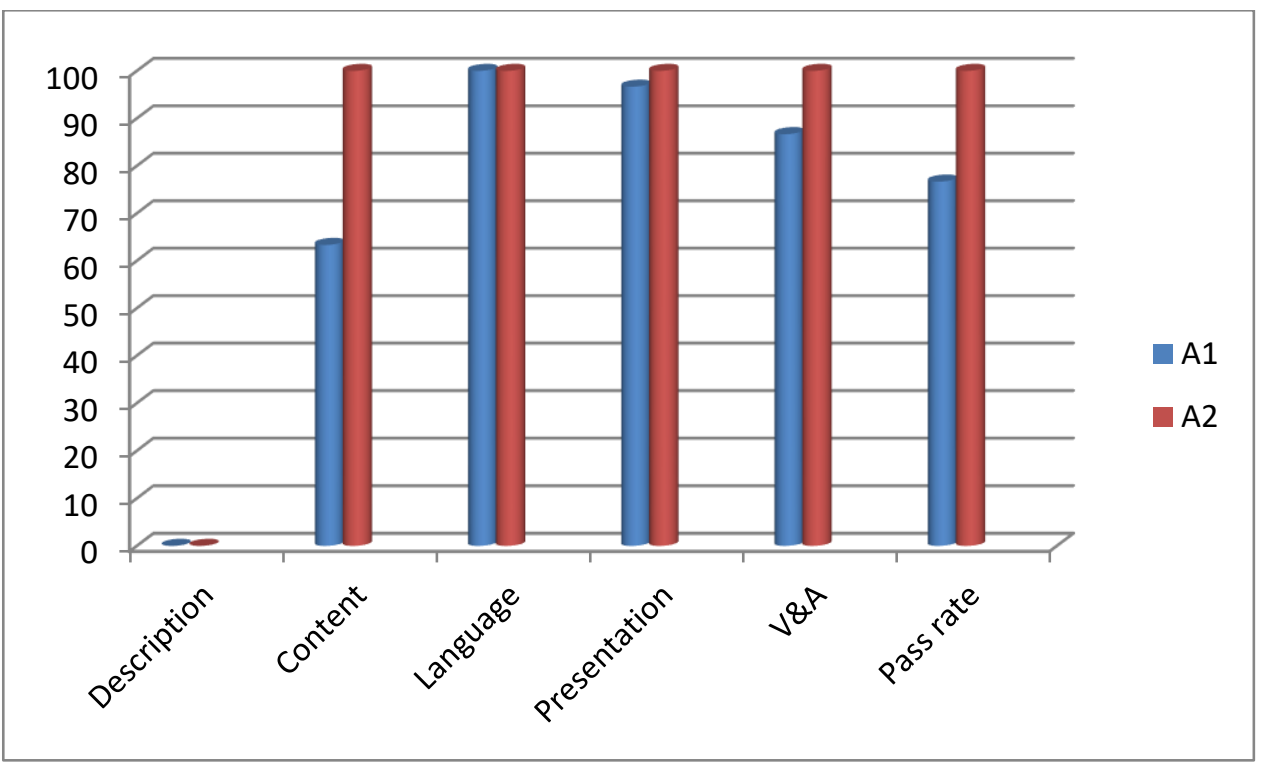

Figure 3: Assessors' pass rates for each marking rubric and overall pass

From the graph, one notes that the second assessor's pass rates for each marking rubric are consistently higher than those of the first assessor, which may mean that either the first assessor was too strict or the second assessor was too lenient. The disparity may also suggest that the marking of essays in poetry is subjective, even with the use of the same marking criteria, as each assessor prioritises different content-related matters. Of significance is the fact that the marks for seven students were upgraded from fail to pass whereas no student's mark was downgraded from pass to fail. Holistically, therefore, both assessors' marks suggest that the lecturer's use of assessment for formative purposes had a positive impact as it enabled students to gain both conceptual and technical knowledge which they then applied to upgrade their essays to the desired level. The decision to not grade the FormA task allowed students to correct their mistakes. Evidently, students saw this as a great opportunity for self-improvement and invested more effort into writing their final essays, thereby acquiring high marks in the SummA task.

\section{Questionnaires}

Since pass rates are not the ultimate indicators of the impact of FormA on students' learning, the questionnaires become valuable in pointing out specific ways in which the feedback assisted students in improving their work. Of the 30 students, 8 completed and submitted the questionnaires. A thematic analysis of their responses to the closed questions revealed that the feedback had helped them in three dominant ways: to see the mistakes in their essays, to know what the lecturer expected their essays to focus on, and to edit their work before submission. In 
terms of language, students found the feedback on sentence construction, punctuation, grammar, omission, spelling, use of tense, and vocabulary useful in improving their work. In terms of writing style, students appreciated the feedback on quoting correctly from the poems, acknowledging their sources, using textual evidence to back up their arguments, making a clear argument, and writing a good introduction. With reference to skills acquisition, they had acquired skills in contextualising their essays, referencing correctly, structuring their essays for coherence of arguments, inferring meaning from poems, writing a good introduction, and writing the titles of poems correctly.

Further analysis of students' responses to the open-ended questions revealed that they believed these skills will be useful to them in the future. The following verbatim statements from four of the students support this finding:

Respondent 1: "The skill will help me to know how to write good essays as I know the format of how to write an essay."

Respondent 2: "The skills are going to help me in writing good essays in all my modules."

Respondent 3: "They will help me not to have difficulties in the next assignment. They will also help me to read question with understanding and answer it based on lecturers' expectations. It has been difficult to understand all procedures in answering poetry questions, but the lecturers' feedback will make it easy for me in the future and also enhance my achievement."

Respondent 4: "They will help me do in-text referencing by so doing I'll be acknowledging information sources I've used, and construct a good literary work. Moreover to improve my English thus will enhance my vocabulary in problem solving."

The responses convey students' appreciation of the usefulness of their acquired skills in helping them to write coherent and well-structured essays in future (in both their ES modules and other modules), to understand lecturers' expectations for an essay, to write in comprehensible English, and ultimately to pass.

Lastly, students' responses to the questionnaires confirm that FormA had significant benefits for students, not only in improving their academic performances and developing their skills for lifelong learning but also in building their confidence in their own abilities. The following four verbatim responses from students attest to this point:

Respondent 5: "It helps students identify their strengths and weaknesses and target areas that need work."

Respondent 6: "Yes. It helps us as students to know where we committed mistakes in our assignments and in a way this helps us to learn not to commit the same mistake again. It also helps us to build ourselves esteem as we know that we excel on the activities which we are challenged with."

Respondent 7: "It is useful to us students and a great method at which lecturers can give feedback 
to students. It shows the students the mistakes and gives them room for improvement."

Respondent 8: "I find formative assessment very useful because it shapes us to what to expect during exam and how to have a meaningful and beautifully structured essays. Our vocabulary and syntax improves through formative assessment."

These responses highlight students' positive responses to the FormA task as well as their appreciation for the feedback that was given.

\section{Document analysis}

Findings from the document analysis corroborate the findings from the questionnaires. A significant improvement was noted in the essays that students submitted for grading purposes, which suggests that students had experienced learning as they had considered the formative feedback provided on their draft essays. A thematic analysis of the final essays revealed the following about the essays:

- They included introductions where none were present before

- They articulated arguments that showed evidence of logical thinking and coherent writing

- They adhered to the directives for presentation stipulated in the feedback documents

- They defined key words and explained key notions in the introductory part of the essays

- $\quad$ They made use of quotation marks to indicate titles of poems

- $\quad$ They referenced correctly and at the appropriate places

- $\quad$ They quoted textual evidence from the poems to substantiate arguments

- They made connections between the historical context of the poems and the thematic concerns of the poems

- $\quad$ They included a reference list where none was initially provided

- They had clearly demarcated concluding paragraphs where none existed before

- $\quad$ They made minimal repetition of ideas

- They had appropriate punctuation where run-on sentences had been used

- They utilised the present tense where the past tense had been dominant

- They made distinctions between poems about colonialism in general and those about apartheid specifically

- $\quad$ They discarded irrelevant ideas included previously

- $\quad$ They inserted content pages where none appeared before

- They identified and explained figures of speech in poems

- They drew links between apartheid and colonialism, while also showing their difference 
in meaning

- They stated arguments to introduce new paragraphs rather than simply quoting lines from the poems

- They constructed effective conclusions that reiterated the essays' major arguments

- They interpreted the essay topic correctly and identified the poems in the introductions.

The following four examples provide evidence to some of the findings listed above.

\section{Example 1}

This essay initially had no introduction; the student had launched straight into the analysis of poems. The feedback comment requested for an introduction and the revised essay had the following introduction:

"It is important to note what colonialism and apartheid has done in our country. The two poems we are going to analyse show us that south Africa was deeply eaten by what it has experienced as a result of the oppression and suffering that colonialism and apartheid has caused. Colonialism has affected people in all stages of their lives whereas apartheid was used as a tool by colonialist to sustain its powers."

\section{Example 2}

This essay initially made a claim about the restriction of the mobility of black people in urban areas, as conveyed in "The Loneliness Beyond", without putting the claim in its proper historical context. In the revised essay, the argument was re-stated as follows:

"From line three of the first stanza "Then as torrent the rush of feet" this line suggest that the people the poet sees are always rushing to work because they don't want to miss their trains and as they come back from work they are rushing to their homes because they don't want to be caught in the cities very late as it was illegal during the apartheid era for blacks to parade the cities during late hours of the day."

\section{Example 3}

This essay did not have a conclusion in the first draft; the analysis ended without a reiteration of the essay's main thrust. In response to the feedback, the revised essay included the following conclusion:

"The relationship between the poems; Crying of South Africa and 'The Loneliness Beyond' is that they both capture the effects of colonialism in the country (South Africa) particularly on the indigenous people. The two poems also show that apartheid did not only disturb the people physically and politically, but also emotionally and psychologically because the pain of discrimination was imprinted in their psychic to the extent that they suffered deep senses of loneliness and grief." 


\section{Example 4}

With reference to "The Loneliness Beyond", this essay initially claimed that "colonialism...is evident when these workers all stay in informal settlements where they live in shacks and their movements in the city were monitored and restricted". In the revised essay, the argument was refined to focus on a single idea and to provide both greater clarity and textual evidence:

"Colonialism in this case, is displayed when these workers all stay in settlements that were far from their places of work i.e. the city; this is evident in their boarding of the train when going to work."

All four examples illustrate that students had applied the feedback which they found valuable and felt would help them earn pass marks in the final essays.

\section{DISCUSSION}

As a reminder, the hypothesis for this experiment was that where there is constructive alignment (alignment between course objectives and course outcomes as well as course outcomes and assessment tasks), transparency in assessment and effective feedback in teaching, there will also be effective learning and higher academic performance by students. The results of the experiment confirm the hypothesis since they show that the ES students achieved high pass rates in their SummA poetry task and also learned academic skills that will serve them longterm. The findings emerging from the experiment suggest that constructive alignment, transparency in assessment and effective feedback are key strategies in FormA, the application of which not only enhances student learning but also helps improve pass rates in HEIs. Nevertheless, these findings also suggest some re-thinking of these strategies and their application in T\&L. It is therefore important to examine some of the implications these strategies have for FormA theory and practice.

\section{Constructive alignment}

When designing the FormA task for the poetry class, the lecturer chose an essay topic that was meant to prompt students to analysis the given poems against the backdrop of historical and political events in South Africa, and not in isolation. The relevant events were discussed in class and also included in the lecture notes provided for students via Blackboard. However, the formative essays suggest that not all the students recognised the need to situate their essays within the relevant historical contexts. In analysing "The Cry of South Africa", many students made reference to the war in general terms, not being specific that it was the South African War. Others interpreted the poem within the context of apartheid (which only came into 
existence in 1948) rather than colonialism, while some interpreted "The Loneliness Beyond" within the context of colonialism in general rather than apartheid specifically. All of this suggests that although the idea of aligning course outcomes to assessment tasks was important for the lecturer, it did not mean much to students. Ensuring that there is constructive alignment when designing a formative task does not necessarily guarantee that students will understand the expectations of the task. This is where feedback with clear instructional correctives becomes crucial. As Wiliam $(2010,27)$ notes, "the best formative assessment ... identifies recipes for future action". In the experiment, it was only in their summative essays that students demonstrated sound understanding of the poems' historical contexts and the value of interpreting the poems in deference to these contexts. This suggests that the feedback influenced their thinking around the essay topic and ultimately their writing of their revised essays. Therefore, the concept of constructive alignment is neither fixed nor implementable in a linear order; rather, it is amenable to the realities of the classroom and largely shaped by the specific context of pedagogic practice.

\section{Transparency in assessment}

While the positive results from this experiment are easily attributed to students' application of formative feedback in writing their final essays, such results also derived from the dissemination of marking criteria during the feedback sessions. Transparency in this case ensured that marking was in line with the criteria. To illustrate, since subject knowledge alone accounted for 50 per cent of the scores, students made efforts to satisfy the criteria for language (20\%), presentation (20\%), and values and attitudes (10\%). Therefore, a student who scored 25 per cent for content, 12 per cent for language, 14 per cent for presentation, and 7 per cent for values and attitudes had a final mark of 58 per cent. This explains why the majority of the students $(56.7 \%)$ fell within the adequate pass $(50-65 \%)$ bracket. Providing and explaining marking criteria to students thus contributes to making assessment yield positive results for all involved. This view is supported by findings from a study by Wilson (2014) which also noted that explaining marking criteria to students helped them to understand what they needed to do to improve their conversation skills. Thus, the availability and explication of success criteria engenders effective learning for students. By contrast, where criteria are neither available nor explained, students are cheated of self-empowering possibilities.

\section{Effective feedback}

What was central to the success of this intervention was the implementation of a multidimensional feedback system involving five types of feedback: in-text written feedback, 
in-class verbal feedback, in-class practical feedback, in-class peer review, and online written feedback. Nicol and Macfarlane-Dick (2006) assert that meaningful feedback motivates students to reflect critically on their writing and to take ownership of their learning. In line with this assertion, one can argue that the feedback provided on students' formative essays was target-oriented, leading to improved writing. Reading the detailed feedback, students also gained insights into the lecturer's expectations, in addition to the expectations highlighted in the assessment criteria.

A significant point to make, however, is that although students largely implemented the feedback in re-writing their essays, they also ignored some of it. The kind of feedback ignored and the subtlety or conspicuousness with which this was done is a subject for another research inquiry. For now, what needs to be noted is that the findings from the experiment with regard to feedback seem to endorse the view that the quantity and quality of feedback given to students have implications for what they learn and how they learn it (Nicol and Macfarlane-Dick 2006). The findings also suggest that feedback does not work in isolation to enhance students' learning. Black and Wiliam $(2009,24)$ argue that there is no direct correlation between the provision of feedback and students' implementation of it: "it does not follow that learners will work on any feedback; both the commitment and the confidence of students will affect the response".

Whether feedback is implemented or not is largely determined by both the constraints of time and the personal circumstances of students. These circumstances include students' internal motivation, external motivation from peers and family, access to a computer, the status of the course for the student (elective or major), and personality traits (whether they are open or resistant to correction). Therefore, although it is argued that FormA flourishes where lecturers provide purposeful feedback, it must equally be argued that the value of the feedback is not in its existence but in its use by students to advance from current to desired performance, to enrich their knowledge base, to enhance their critical thinking skills, and to learn new skills and values useful for social upward mobility.

\section{CONCLUSION}

This experiment with third-year ES students at UL yielded results which confirm that the practical implementation of FormA strategies significantly improves students' academic performance as well as their lifelong learning. The students involved in this intervention developed skills in conceptualising ideas, thinking critically, writing coherently, referencing correctly, and editing their own work. They also came to appreciate values such as academic honesty and obedience to instructions, while developing a positive attitude towards hard work.

As intimated previously, however, the results of this experiment also suggest that FormA 
alone does not guarantee students' academic success or their acquisition of quality education. It is necessary to take into consideration other factors such as students' class attendance, personal motivation, and commitment to the learning process, all which influence students' learning. In addition, students' overall university experience can affect their academic performance negatively or positively. Therefore, the designing and implementation of FormA in T\&L should be done holistically across the university such that the benefits reaped in one course are not undermined by poor or no implementation in other courses.

In conclusion, it must be stated that, although highly valuable, applying FormA strategies in T\&L at universities is not an easy task. The experiment with third-year ES students at UL shows that the project is time-consuming, labour-intensive, emotionally tasking, and limited to small classes. Considering that university teaching timetables do not make provision for lengthy feedback sessions as lecturers are under pressure to cover their curriculums, it can be a real challenge to make practical application of FormA. This study however indicates that the rewards are massive if measured in terms of students' increased skills development, improved academic performance, and enhanced self-confidence. Such an intervention is also an effective and practical way of building a strong relationship with students as lecturers get to understand each one's unique challenges. With this close relationship and equal commitment to the practice of FormA, success is a real possibility.

\section{REFERENCES}

Abrams, L. 2007. Implications of high-stakes testing for the use of formative classroom assessment. In Formative classroom assessment: Theory into practice, ed. J. H. Macmillan, 79-98. New York: Teachers College Press.

Akoojee, S. and M. Nkomo. 2007. Access and quality in South African higher education: The twin challenges of transformation. South African Journal of Higher Education 21(3): 385-399.

Bennett, R. E. 2011. Formative assessment: A critical review. Assessment in Education: Principles, Policy \& Practice 18(1): 5-25.

Biggs, J. 1999. What the student does: Teaching for enhanced learning. Higher Education Research \& Development 18(1): 57-75.

Black, P. and D. Wiliam. 2009. Developing the theory of formative assessment. Educational Assessment, Evaluation and Accountability 21: 5-31.

Brydon-Miller, M., M. Kral, P. Maguire, S. Noffke and A. Sabhlok. 2013. Jazz and the banyan tree: Roots and riffs on participatory action research. In Strategies of qualitative inquiry, eds. N. K. Denzin and Y. S. Lincoln, 347-375. Thousand Oaks, California: Sage.

Cizek, G. 2010. An introduction to formative assessment: History, characteristics, and challenges. In Handbook of formative assessment, ed. H. L. Andrade and G. J. Cizek, 3-17. New York: Routledge.

Council for Higher Education. 2011. Audit report on the University of Limpopo. Pretoria: CHE.

Gibbs, G. 1999. Using assessment strategically to change the way students learn. In Assessment matters in higher education, ed. S. Brown and A. Glasner, 41-53. Buckingham: SRHE and Open University Press. 
Gikandi, J. W., D. Morrow and N. E. Davis. 2011. Online formative assessment in higher education: A review of the literature. Computers \& Education 57: 2333-2351.

Knight, P. 2001. A briefing on key concepts: Formative and summative criterion and norm-referenced assessment. New York: Learning and Teaching Support Network Generic Centre Assessment Series No 7.

Leach, N. 2014. Formative computer-based assessments to enhance teaching and learning. South African Journal of Higher Education 28(3): 1033-1046.

Liu, Y. 2013. Preliminary study on application of formative assessment in college English writing class. Theory and Practice in Language Studies 3(12): 2186-2195.

Marshall, B. 2007. Formative classroom assessment in English, the Humanities, and Social Sciences. In Formative classroom assessment: Theory into practice, ed. J. H. Macmillan, 136-151. New York: Teachers College Press.

Meyer, L., K. Lombard, P. Warnich and C. Wolhuter. 2010. Outcomes-based assessment for South African teachers. Pretoria: Van Schaik.

Nicol, D. J. and D. Macfarlane-Dick. 2006. Formative assessment and self-regulated learning: A model and seven principles of good feedback practice. Studies in Higher Education 31(2): 199-218.

Pryor, J. and C. Lubisi. 2002. Reconceptualising educational assessment in South Africa - testing times for teachers. International Journal of Educational Development 22: 673-686.

Ramsden, P. 1992. Learning to teach in higher education. London: Routledge.

Ribbens, R. 2008. Hypnotised by Gutenberg? A report on the reading habits of some learners in academia. Journal of Language Teaching 42(2): 105-122.

Shepard, L. 2000. The role of assessment in a learning culture. Educational Researcher 29(7): 4-14.

Symes, A. 2006. Democratisation and quality assurance in South African higher education. South African Journal of Higher Education 20(6): 762-772.

Yorke, M. 2003. Formative assessment in higher education: Moves towards theory and the enhancement of pedagogic practice. Higher Education 45: 477-501.

Wiliam, D. 2010. An integrative summary of the research literature and implications for a new theory of formative assessment. In Handbook of formative assessment, ed. H. L. Andrade and G. J. Cizek, 18-40. New York: Routledge.

Wilson, C. 2014. Formative assessment in university English conversation classes. Studies in Self-access Learning Journal 5(4): 423-429. http://sisaljournal.org/archives/dec14/wilson.

Wolcott, H. F. 1992. Posturing in qualitative inquiry. In The handbook of qualitative research in education, ed. M. D. LeCompte, W. L. Millroy and J. Preissle, 3-51. San Diego, California: Academic Press. 